Article

\title{
An Overview of Vehicular Communications
}

\author{
Fabio Arena and Giovanni Pau *(D)
}

Faculty of Engineering and Architecture, Kore University of Enna, Cittadella Universitaria, 94100 Enna, Italy; fabio.arena@unikore.it

* Correspondence: giovanni.pau@unikore.it; Tel.: +39-093-553-6494

Received: 29 December 2018; Accepted: 22 January 2019; Published: 24 January 2019

\begin{abstract}
The transport sector is commonly subordinate to several issues, such as traffic congestion and accidents. Despite this, in recent years, it is also evolving with regard to cooperation between vehicles. The fundamental objective of this trend is to increase road safety, attempting to anticipate the circumstances of potential danger. Vehicle-to-Vehicle (V2V), Vehicle-to-Infrastructure (V2I) and Vehicle-to-Everything (V2X) technologies strive to give communication models that can be employed by vehicles in different application contexts. The resulting infrastructure is an ad-hoc mesh network whose nodes are not only vehicles but also all mobile devices equipped with wireless modules. The interaction between the multiple connected entities consists of information exchange through the adoption of suitable communication protocols. The main aim of the review carried out in this paper is to examine and assess the most relevant systems, applications, and communication protocols that will distinguish the future road infrastructures used by vehicles. The results of the investigation reveal the real benefits that technological cooperation can involve in road safety.
\end{abstract}

Keywords: vehicular communications; V2V; V2I; V2X; intelligent transportation system; road safety

\section{Introduction}

The transport field has noticed particular development in recent years thanks to the application of intelligent systems. Traditional transport arrangements have been supplanted by Intelligent Transport Systems (ITSs) [1-3]. These new technologies are assisting in solving the main problems of transport engineering, i.e., traffic congestion and accidents. Nevertheless, these systems must be able to cooperate, for instance, allowing the communication with and among vehicles [4]. The interaction between the various involved entities requires the information exchange to use proper communication protocols, such as the IEEE 802.11p [5,6] and LTE-V2V [7,8] standards, designed to support vehicle transmissions $[9,10]$. In more detail, the IEEE $802.11 \mathrm{p}$ standard has explicitly been introduced for Wireless Access in Vehicular Environments (WAVE). It is intended to facilitate V2V and V2I communications. Its distinctive design facilitates the coordination and the cooperation between vehicles and infrastructures [11]. The IEEE 802.11p gives data rate ranging from $6 \mathrm{Mbps}$ to $27 \mathrm{Mbps}$ at short radio transmission distance, around $300 \mathrm{~m}$. As an alternative to the IEEE $802.11 \mathrm{p}$, the usage of cellular technologies has been evaluated for vehicular communications [12]. The fundamental enabler of such usage is the standardization of the Third-Generation Partnership Project (3GPP) which implements effective message distribution to multiple users over a geographical area at a well-made granularity. The third generation of mobile cellular systems is well known as the Universal Mobile Telecommunication System (UMTS), while the fourth generation is denominated Long-Term Evolution (LTE). It is a progression of the UMTS that increases the capacity and speed using a different radio interface together with core network improvements. The LTE features provide downlink peak rates of $300 \mathrm{Mbps}$, uplink peak ones of $75 \mathrm{Mbps}$, transfer latency of less than $5 \mathrm{~ms}$, and a transmission range up to $100 \mathrm{~km}$ in the radio network. 
Other protocols that can be used in vehicular communications are Bluetooth [13] and IEEE 802.15.4/ZigBee [14], adequately revised [15]. The main aim of all the cited standards is to reduce the connection times and to extend the transmission range, allowing proper operation in conditions of high mobility and vehicular density. In the transport research field, the primary purpose of these technologies is the improvement of road safety, trying to prevent any dangerous situations. In this context, the V2V (Vehicle-to-Vehicle) [16,17], V2I (Vehicle-to-Infrastructure) [18,19], and V2X (Vehicle-to-Everything) [20,21] technologies intends to provide communication models that can be used by vehicles in different application contexts. The resulting infrastructure is an ad-hoc mesh network whose nodes are not just vehicles, but all mobile devices equipped with a wireless module.

The main intention of the review carried out in this paper is to prove that the introduction of these intelligent systems in transport engineering leads to authentic advantages for road safety. One of the significant areas of interest in today's vehicular industry is the development of technological solutions aimed at improving road safety. To this end, several solutions have been installed in the cars currently available on the market, such as anti-collision sensors [22], intelligent navigation systems [23], driver notification systems [24], assisted parking systems [25], and autonomous driving [26]. However, each company uses proprietary technologies that are unable to interact and cooperate with the equipment installed in vehicles fabricated by other manufacturers. Precisely for these reasons, it is essential to create a standardized system that can interoperate all over the world, providing an easy and effective integration between all these services and applications on the market [27-30].

It is necessary to note that the term V2X encompasses all types of communications involving vehicles, including V2V and V2I. However, in the review carried out in this paper, these three communication areas are analyzed separately to highlight in more detail the distinctiveness of each of them. This paper is organized as follows: Section 2 is focused on $V 2 V$, presenting the primary systems and applications that best meet the requirements necessary for the realization of effective technological cooperation among vehicles. Sections 3 and 4 introduces the main features of V2I and V2X, respectively. Finally, Section 5 gives conclusive remarks for the paper along with future directions.

\section{Vehicle-To-Vehicle}

$\mathrm{V} 2 \mathrm{~V}$ technology consists of wireless data transmissions between motor vehicles. The primary purpose of this communication is to prevent possible accidents, allowing vehicles in transit to transfer data on their position and their speed within an ad-hoc mesh network [31]. The latter uses a decentralized connection system, which may provide either a fully connected mesh topology or a partially connected mesh topology (Figure 1). In the first case, each node is connected directly to others in the network. In the second case, some nodes can be connected to all the others, while the remaining ones are attached only to those with which they frequently exchange most of the data. By exploiting this network topology, the nodes of a mesh network can exchange messages and information with neighboring nodes to which they are directly connected (only one hop, in the case of totally connected network), or they can choose one of the different paths available to reach the destination (multi-hop, in the case of a partially connected network). This topology also increases the robustness of the network structure. In fact, in case of collapse or temporary malfunction of a node, the routes are recalculated within the forwarding tables to reach all destinations.

In the past, when mesh networks were only wired, this topology was very expensive and difficult to realize, because each node had to be physically connected to the others. Today, by employing the advantages introduced by wireless communications and with the appearance of the Wireless Personal Area Networks (WPANs), these limitations have been overcome. In these networks, each autonomous and mobile node, connected to the others, forms a graph of arbitrary size (partially connected mesh network). Instead of relying on a base station that coordinates the flow of messages to each entity in the network, the individual nodes forward the packets to each other. These nodes can move randomly and organize themselves arbitrarily, although wireless topology varies rapidly and 
unpredictably. Furthermore, these networks can operate alone or be connected to the Internet to provide additional services.
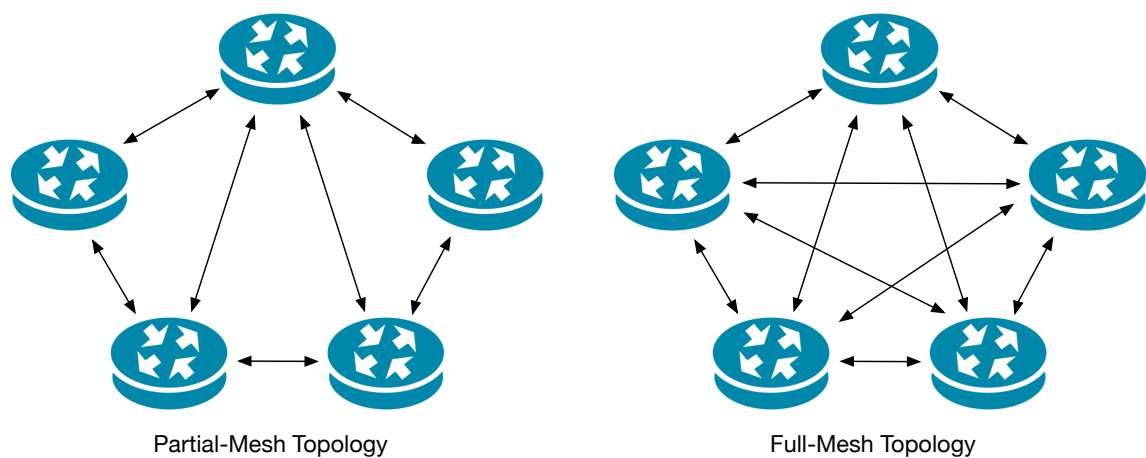

Figure 1. Mesh topologies.

Depending on how the technology is developed, the driver of a vehicle can receive a warning in the event of an accident risk or the vehicle itself can independently take preventive actions, such as emergency braking, if it is designed to carry out safety interventions [32]. It is expected that $\mathrm{V} 2 \mathrm{~V}$ communications will be far more effective than current embedded systems designed by the Original Equipment Manufacturer (OEM) since, to date, the vehicle safety is entirely dependent on the functionality of onboard sensors, cameras, and radars [33]. The system reacts to any dangerous situations based on specific parameters detected by these devices placed on the vehicle. Typically, the main examined parameters are the travel speed, the distance from an obstacle or the presence of a vehicle in the blind spot. However, although the used technologies are increasingly reliable, the calculation errors should not be underestimated. On the contrary, V2V communication protocols will improve the performance in the security field, since, by making all the vehicles close to interact each other, they will help the car in danger (for instance, driver's sleep, a component malfunction, obstacle in the lane, and so on) to undertake a more effective choice to solve the emerging problem. Therefore, the primary purpose of each node forming part of the mesh network will be the data collection to guarantee good security to itself and its neighbors. This system is called cooperative awareness [34]. Anyhow, it is useful to adopt proper coding methods for real-time data access, as suggested in $[35,36]$.

An overview of the current autonomous OEM security systems (used in the latest generation vehicles) will provide complete knowledge of the technologies currently available on the market. The central OEM systems today widespread are the following:

- $\quad$ Blind Spot Monitoring (BSM) [37]: it is an assistance system that monitors the blind spots of the exterior rear-view mirrors, using radar sensors. This system informs the driver of a vehicle arrival with a visual signal integrated into the two left and right rear-view mirrors, based on the side where the vehicle in front passes.

- Anti-Schlupf Regierung (ASR), also known as Traction Control System (TCS) or Automatic Stability Control (ASC) [38]: it is a system aimed at regulation and control of the sliding of the wheels during acceleration which, similarly to the homologous system for the braking control, allows to better control the traction in the starting phase (and during the cruise phase), according to the conditions of the road surface.

- Electronic Stability Program (ESP) [39]: it is a device that acts when the vehicle shows signs of lateral heeling (yaw), i.e., in the event of oversteer or understeer movements. Therefore, it allows the vehicle to maintain the correct trajectory and to go not out of the way.

- Forward Collision Warning (FCW) [40]: it is a system based on radar sensors that monitor the road. This system recognizes the objects and detects the distance between the vehicle and the likely obstacles on the road: if the speed of travel is a risk of imminent collision, the driver can be alerted through acoustic sensors or light signals on the onboard display. 
- Automatic Emergency Braking (AEB) [41]: it is an assisted emergency braking system that combines advanced driver assistance with electronic stability control to slow down the vehicle and potentially reduce the severity of the impact when the collision is unavoidable. If the driver brakes inadequately or does not brake at all (for instance, due to a sleep blow), the pre-crash system acts by arranging various components of the car to mitigate the impact. In this way, for instance, the belts are stretched to the maximum, air is pumped into the airbags, the windows and the sunroof are closed, to prevent damage to the occupants, in the event of the vehicle overturning, and the brake intervenes slightly to reduce impact violence, also attracting the driver's attention. If installed in the vehicle, the active head restraints are inclined forward to prevent whiplash injuries in the impact.

- Brake Assist System (BAS) [42]: it is an active device mounted on the vehicle's braking system which only comes into operation in the event of sudden emergency braking, when the brake pedal is pressed very quickly but without the necessary pressure to activate the ABS (or anti-lock system). It is an electronic control unit that avoids the locking of the wheels of the vehicles ensuring the drivability during the braking. In this case, the BAS activates the automatic raising of the pressure on the pedal, until the correct functioning of the ABS on all the wheels, thus ensuring a better braking action.

- $\quad$ Lane Departure Warning System (LDWS) [43]: it is a device that warns the distracted driver of exceeding the line that delimits its lane. It is activated through a switch on the center console and warns the driver with a slight acoustic signal if the vehicle passes one of the lane lines without an apparent reason, for instance, without using the direction indicator.

The V2V technology, thanks to the cooperation with these already existing security systems, will yield efficient management of possible pitfalls in the roadways all over the world. The new Intelligent Transport Systems (ITSs) will employ data from V2V communication to enhance traffic management, allowing vehicles to also communicate with road infrastructures, such as traffic lights or signs. These technologies could become mandatory in the not too distant future and contribute to building more reliable self-driving cars on motorways. Nevertheless, the implementation of V2V communications and an intelligent transport system involves three main obstacles: the need for car manufacturers to agree with rules of security and operation; the guarantee of privacy and confidentiality of data sent in broadcast and multicast; the financing necessary for the development and dissemination of all technology.

At the moment, it is not clear whether public or private subjects will finance the creation and maintenance of the network infrastructure. However, among the leading car manufacturers who are working on ITS systems and V2V communications indeed it is useful to mention General Motors, BMW, Audi, Daimler, and Volvo. In the last five years, the evaluation of prototypes concerning $\mathrm{V} 2 \mathrm{~V}$ applications has been the focus of the research and development of many vehicles all over the world, especially, in the USA [44]. As a result, of these works, some experimental prototypes have been developed to estimate the environmental impacts, challenging to observe today due to the lack of a standard, and to the potential future impacts due to a broad hypothetical adhesion of applications in the field of vehicular communications, through a series of analytical methods. The USDOT (Department of Transportation of the United States of America) has documented the implementation and development of the most advanced applications, including the requirements of systems, design documents, algorithms and source codes associated with prototypes [45]. Table 1 presents some of the applications for connected vehicles, arranged by USDOT. 
Table 1. Applications for connected vehicles.

\begin{tabular}{|c|c|c|}
\hline V2V Safety & Agency Data/Environment & Smart Roadside/Mobility \\
\hline $\begin{array}{l}\text { Emergency Electronic } \\
\text { Brake Lights (EEBL) }\end{array}$ & $\begin{array}{c}\text { Probe-based Pavement } \\
\text { Maintenance }\end{array}$ & Wireless Inspection \\
\hline $\begin{array}{l}\text { Forward Collision } \\
\text { Warning (FCW) }\end{array}$ & $\begin{array}{l}\text { Probe-enabled Traffic } \\
\text { Monitoring }\end{array}$ & Smart Truck Parking \\
\hline $\begin{array}{l}\text { Intersection Movement } \\
\text { Assist (IMA) }\end{array}$ & $\begin{array}{c}\text { Vehicle Classification-based } \\
\text { Traffic Studies }\end{array}$ & $\begin{array}{l}\text { Intelligent Traffic Signal } \\
\text { System (I-SIG) }\end{array}$ \\
\hline $\begin{array}{l}\text { Left Turn Assist } \\
\text { (LTA) }\end{array}$ & $\begin{array}{l}\text { CV-enabled Turning Movement } \\
\text { \& Intersection Analysis }\end{array}$ & $\begin{array}{l}\text { Signal Priority } \\
\text { (transit, freight) }\end{array}$ \\
\hline $\begin{array}{l}\text { Blind Spot/Lane } \\
\text { Change Warning }\end{array}$ & $\begin{array}{c}\text { CV-enabled Origin-Destination } \\
\text { Studies }\end{array}$ & $\begin{array}{l}\text { Cooperative Adaptive } \\
\text { Cruise Control (CACC) }\end{array}$ \\
\hline $\begin{array}{l}\text { Curve Speed } \\
\text { Warning }\end{array}$ & $\begin{array}{l}\text { Work Zone Traveler } \\
\text { Information }\end{array}$ & $\begin{array}{l}\text { Guidance for } \\
\text { Emergency }\end{array}$ \\
\hline $\begin{array}{c}\text { Do Not Pass } \\
\text { Warning (DNPW) }\end{array}$ & $\begin{array}{c}\text { Dynamic Eco-Routing } \\
\text { (light, vehicle, transit, freight) }\end{array}$ & $\begin{array}{l}\text { Emergency Communications } \\
\text { and Evacuation (EVAC) }\end{array}$ \\
\hline $\begin{array}{l}\text { Vehicle Turning } \\
\text { Right in Front of }\end{array}$ & $\begin{array}{l}\text { Low Emissions Zone } \\
\text { Management }\end{array}$ & $\begin{array}{l}\text { Connection Protection } \\
\text { (T-CONNECT) }\end{array}$ \\
\hline $\begin{array}{l}\text { Bus Warning } \\
\quad \text { (transit) }\end{array}$ & $\begin{array}{l}\text { Eco-ICM Decision } \\
\text { Support System }\end{array}$ & $\begin{array}{l}\text { Freight-Specific } \\
\text { Dynamic Travel }\end{array}$ \\
\hline $\begin{array}{l}\text { Queue Warning } \\
\text { (Q-WARN) }\end{array}$ & $\begin{array}{l}\text { Eco-Smart } \\
\text { Parking }\end{array}$ & $\begin{array}{c}\text { Emergency Vehicle } \\
\text { Preemption (PREEMPT) }\end{array}$ \\
\hline
\end{tabular}

\section{Vehicle-To-Infrastructure}

Unlike the $\mathrm{V} 2 \mathrm{~V}$ communication model, which allows the exchange of information only among vehicles, the V2I enables vehicles in transit to interface with the road system. These components include RFID readers, traffic lights, cameras, lane markers, street lamps, signage, and parking meters [46]. Commonly, V2I communications are wireless, bidirectional, and similarly to V2V, using Dedicated Short-Range Communication (DSRC) frequencies to transfer data [47]. This information is sent from the elements of the infrastructure to the vehicle, or vice versa, through an ad-hoc network. In the ITS, V2I sensors can acquire infrastructural data and provide travelers with real-time advice, sending information on road conditions, traffic congestion, any accidents in the roadway, the presence of construction sites and the availability of parking spaces. Likewise, traffic supervision and management systems can use the data collected from the infrastructure and vehicles to set variable speed limits and adjust the Signal Phase and Timing (SPaT) to achieve fuel savings and facilitate traffic flows [48]. The hardware, software, and firmware that make communication between vehicles and infrastructure reasonable are a fundamental starting point for the development of autonomously driven cars.

In January 2017, the US Department of Transportation issued V2I guidelines for the Federal Highway Administration (FHA), aimed at improving safety and mobility, accelerating the implementation of communication systems [49]. These guidelines are designed to help state governments in preparing V2I initiatives and managing the data needed to support them. For the realization of these projects, as already mentioned, the problems of financing and obtaining resources arise from governments. Since these costs cannot be sustained only by the income of the states, coming from fuel taxes and motorway tolls, a partnership is needed with the primary vehicle's manufacturers, which could benefit for their commercial purposes of big data used in communications.

\section{Vehicle-To-Everything}

The V2V and V2I communication models mentioned above are completed in the V2X, which represents a generalization. The latter consists in the data transfer from a vehicle to any entity that 
can influence it, or vice versa, and incorporates other more specific types of communication including Vehicle-to-Pedestrian (V2P) [50], Vehicle-to-Roadside (V2R) [51], Vehicle-to-Device (V2D) [52], and Vehicle-to-Grid (V2G) [53]. A broad representation of the V2V, V2I and V2X communications is shown in Figure 2. According to the report on the global state of road safety [54], there are about 1.25 million people died because of road accidents every year around the world. Almost half of the victims were identified as pedestrians, cyclists, and motorcyclists, defined collectively as Vulnerable Road Users (VRU) [55]. It is useful to note that the defects in road design and the lack of proper separation from traffic significantly affect the creation of an unsafe environment for drivers and pedestrians [56]. Another issue that should not be underestimated, especially in urban centers, is the distraction of pedestrians, caused by the use of their earphones and smartphones, frequently handled while walking down the street [57]. Therefore, it is necessary to develop a warning system also for pedestrians.

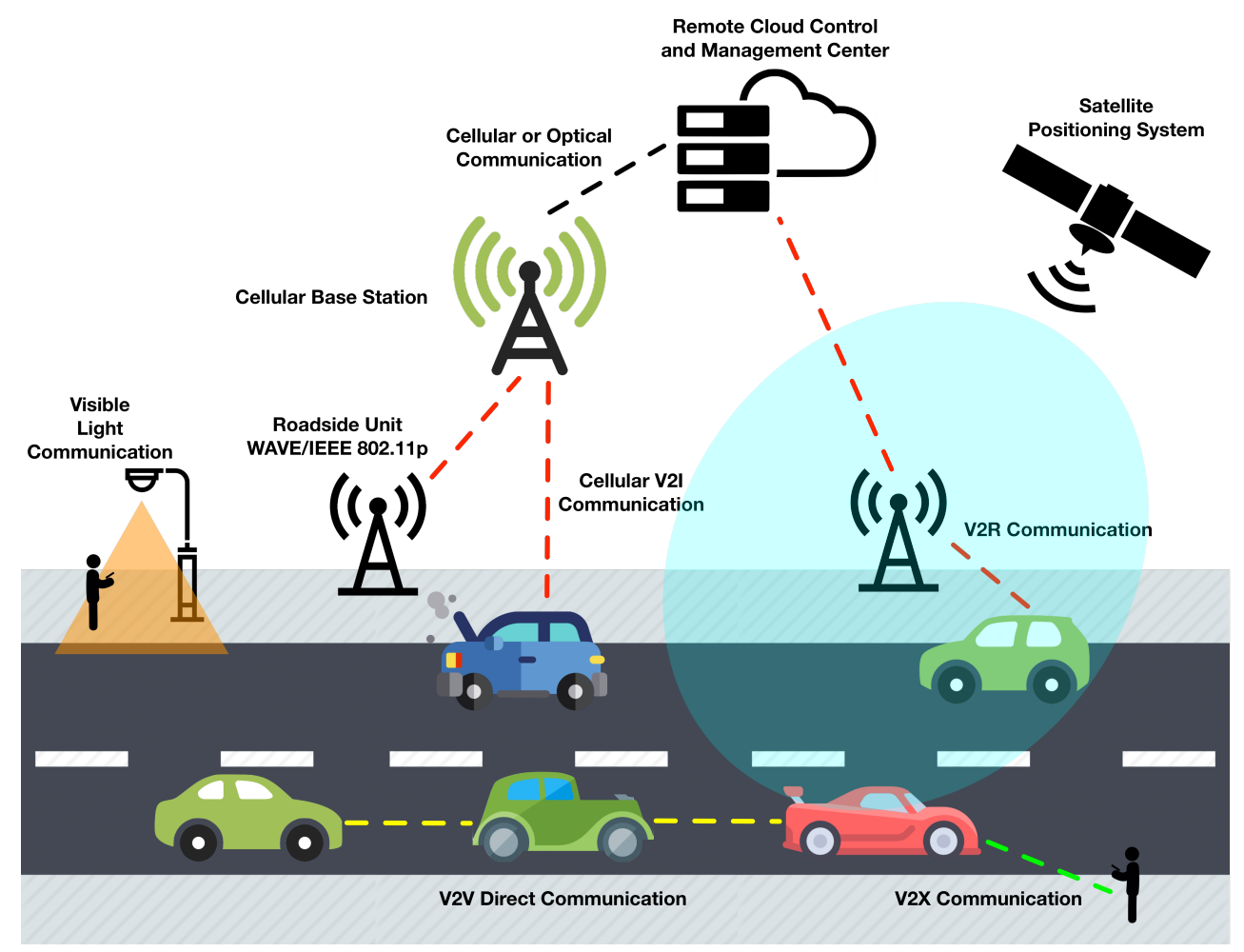

Figure 2. V2V, V2I, and V2X communications.

One of the main purposes of the V2X technology is precisely to support the possible and efficient communication mechanisms between vehicles and pedestrians aimed at limiting accidents, sometimes fatal. Recently, in this direction, the Pedestrian Collision Warning (PCW) has been developed [58,59], which can practice wireless modules included in mobile phones, such as $\mathrm{Wi}-\mathrm{Fi}$, Bluetooth, and Near Field Communication (NFC). In the detection system based on wireless modules included in the PCW architecture, for instance, as the Wi-Fi module competes, an active security mechanism for VRU, which uses beacon stuffing to alert pedestrians to imminent danger, has been introduced in [60]. The same module is employed in V2X communications, applying the Wi-Safe technology [61], but has a fundamental limit that is a unidirectional approach, where only pedestrians receive notices. On the contrary, Wi-Fi Direct [62], a peer-to-peer wireless standard that allows smartphones to communicate directly with each other rather than through an access point, as in cell phone towers, is practiced in [63]. However, Wi-Fi-based approaches have some drawbacks. First of all, a high power consumption, if using the Access Point/Client mode. Furthermore, the values of the packet delivery rate and latency in the scanning period are not as good as in the literature. Therefore, there has been the need for 
native technologies for vehicular communications. In particular, for instance, already several years ago, General Motors evaluated the capabilities of a car equipped with DSRC [64], in V2X contexts [65].

Regarding the V2X and PCW architectures, it can be practiced a prevention system based on cameras and Visible Light Communication (VLC) [66-69]. Nevertheless, this solution is severely influenced by environmental circumstances, because if the weather or road conditions are not right, it can be difficult to obtain accurate data. Furthermore, there are various computational limits in three-dimensional recognition and errors in image processing. Another PCW solution can be represented by a driving assistance system, such as Adaptive Cruise Control (ACC) [70] and the AEB [71], employing millimeter-wave radar [72], LiDAR (Laser Imaging Detection and Ranging) [73], and other specific sensors in the vehicle. These sensors obtain relative speed and distance from objects, calculating the difference in time and frequency respectively between the signals sent and those received. However, a limitation is represented by any weak signals covered by noise or by the application at high travel speeds and the distance between vehicles, which makes the system considered inadequate in complex scenarios. It can be adopted an approach based on Bluetooth Low Energy (BLE) [74] to overcome the limits of Wi-Fi, VLC, and control sensors. This wireless standard can be useful in PCW environments as it allows bidirectional communications with the lowest power consumption and with good reception values. Moreover, it is already installed in all the latest generation smartphones and aims to be the communication standard for the Internet of Things (IoT) [75]. Finally, considering the evolution of the LTE-V2X and the emerging 5G [76], the entirely automated driving and innovative vehicular services can be accomplished with joint innovation through cross-industry collaboration.

\section{Conclusions}

The near future is focused on the application of ITS technologies on roads all over the world. All or parts of existing infrastructures will have to be renewed to achieve this purpose. In this sense, all national governments will have to provide public/private partnerships that will allow them to find the necessary funds for the modernization of the entire road network. It is desirable that these investments will have to provide an economic return compatible with public spending. Considering that transport systems typically depend mainly on data collected from the network, the proper design and management of the communication network is an essential step to distribute the most significant number of applications. This goal will be an essential step to make these systems robust and reliable. Apparently, the timeline can be still as long as it will be necessary to develop appropriate ITS models, more realistic concerning algorithms, analytical formulations, optimization models, and probabilistic approaches.

In the main areas of interest in today's vehicular industry, there is a growing trend aimed at the cooperation between vehicles and, in general, between them and all the types of equipment of the transport sector. The purpose is to improve the safety, comfort and, possibly, also the entertainment of drivers and passengers. Starting from the technologies applied to today's vehicles, which can potentially operate independently, the review carried out in this paper has analyzed the primary systems, applications, and protocols that best meet the requirements necessary for the realization of effective technological cooperation at the service of the road safety. Among the models useful for this purpose, V2V, V2I, and V2X communications play undoubtedly an essential role.

New ITS technologies will need to be integrated even more effectively with existing mobile networks, or that will be developed in future years, in order to definitively implement the so-called IoT, supporting new cloud-based services and Software Defined Networks (SDN), thus generating increasingly sophisticated services. The adoption of these networks in ITS applications is necessary to find the most extensive applicability and real implementation. As a consequence, the diffusion of ITS technologies will have to be also applied on the less frequented roads (i.e., rural areas or zones with low population density) to cover the entire road network of each state. When the coverage of the network cannot be supported, it could be guaranteed by Device-to-Device (D2D) communications and 
future generation mobile communication systems, such as, for instance, the 5G. Furthermore, the use of social networks and the application of crowdsourcing strategies could also represent valuable support for resources management in ITS applications. Contrarily, large private companies will be able to handle large amounts of data from connected mobile devices and vehicles, aimed at undertaking new marketing and sales initiatives.

In conclusion, from the analysis carried out in this paper, it is possible to present in Table 2 the purposes and the downsides that will have to be faced for widespread dissemination of vehicular communications. A fundamental feature will be the maintenance of the road surface and signs that will result in a better application of ITS systems operations. In this case, the main impediment is economic costs as only a small part of the global road infrastructure, at present, could be ready for V2X communications and significant economic resources are required for the improvement of the road network. Another goal to be achieved will be the improvement of the technological infrastructure which will involve the complete and total operation of the V2V, V2I, and V2X communications. Nevertheless, the difficulty to be faced is represented not only by the potentially tricky implementation on a large scale but also by the lack of a common standard used universally. The efficient management and analysis of big data will certainly represent a very profitable opportunity as it could involve not only an economic return for possible private investors but also the retrieval of more detailed information thanks to advanced analysis tools. However, all this will have to guarantee the data privacy. Finally, it is evident that the integration and synergy between ITS systems and the technological infrastructure will bring advantages concerning the improvement of performance in the operation of transport systems and the development of possible new innovative applications. Again, the main challenges are represented by the difficult implementation on a large scale, the economic costs, and the lack of a universal standard.

Table 2. Purposes and downsides of future vehicular communications.

\begin{tabular}{|c|c|c|}
\hline Feature & Advantages & Downsides \\
\hline $\begin{array}{l}\text { Maintenance } \\
\text { of road surface } \\
\text { and signs }\end{array}$ & $\begin{array}{l}\text { - Improvement of ITS } \\
\text { systems performance }\end{array}$ & - Economic costs \\
\hline $\begin{array}{l}\text { Technological } \\
\text { infrastructure }\end{array}$ & $\begin{array}{l}\text { - Full operation of V2V, } \\
\text { V2I, and V2X communications }\end{array}$ & $\begin{array}{c}\text { - Complexity of large-scale } \\
\text { implementation } \\
\text { - Standardization }\end{array}$ \\
\hline $\begin{array}{l}\text { Big Data } \\
\text { management }\end{array}$ & $\begin{array}{l}\text { - Economic returns for } \\
\text { possible private investors } \\
\text { - More information } \\
\text { thanks to analysis }\end{array}$ & - Ensure data privacy \\
\hline $\begin{array}{l}\text { Integration between } \\
\text { ITS systems } \\
\text { and technological } \\
\text { infrastructure }\end{array}$ & $\begin{array}{l}\text { - Improved performance } \\
\text { in system operation } \\
\text { - Development of possible } \\
\text { new future applications }\end{array}$ & $\begin{array}{l}\text { - Complexity of large-scale } \\
\text { implementation } \\
\text { - Standardization } \\
\text { - Economic costs }\end{array}$ \\
\hline
\end{tabular}

Author Contributions: All authors committed to the development and writing of the paper.

Conflicts of Interest: The authors declare no conflict of interest.

\section{References}

1. Ghosh, R.; Pragathi, R.; Ullas, S.; Borra, S. Intelligent transportation systems: A survey. In Proceedings of the 2017 International Conference on Circuits, Controls, and Communications (CCUBE), Bangalore, India, 15-16 December 2017; pp. 160-165.

2. Luckow, A.; Kennedy, K. Data Infrastructure for Intelligent Transportation Systems. In Data Analytics for Intelligent Transportation Systems; Chowdhury, M., Apon, A., Dey, K., Eds.; Elsevier: Amsterdam, The Netherlands, 2017; Chapter 5, pp. 113-129. 
3. Alam, M.; Ferreira, J.; Fonseca, J. Introduction to Intelligent Transportation Systems. In Intelligent Transportation Systems: Dependable Vehicular Communications for Improved Road Safety; Alam, M., Ferreira, J., Fonseca, J., Eds.; Springer International Publishing: Cham, Switzerland, 2016; pp. 1-17.

4. Martin-Vega, F.J.; Soret, B.; Aguayo-Torres, M.C.; Kovacs, I.Z.; Gomez, G. Geolocation-Based Access for Vehicular Communications: Analysis and Optimization via Stochastic Geometry. IEEE Trans. Veh. Technol. 2018, 67, 3069-3084. [CrossRef]

5. Han, C.; Dianati, M.; Tafazolli, R.; Kernchen, R.; Shen, X. Analytical Study of the IEEE 802.11p MAC Sublayer in Vehicular Networks. IEEE Trans. Intell. Transp. Syst. 2012, 13, 873-886. [CrossRef]

6. Bazzi, A.; Campolo, C.; Masini, B.M.; Molinaro, A.; Zanella, A.; Berthet, A.O. Enhancing Cooperative Driving in IEEE 802.11 Vehicular Networks Through Full-Duplex Radios. IEEE Trans. Wirel. Commun. 2018, 17, 2402-2416. [CrossRef]

7. Molina-Masegosa, R.; Gozalvez, J. LTE-V for Sidelink 5G V2X Vehicular Communications: A New 5G Technology for Short-Range Vehicle-to-Everything Communications. IEEE Veh. Technol. Mag. 2017, 12, 30-39. [CrossRef]

8. Bazzi, A.; Cecchini, G.; Zanella, A.; Masini, B.M. Study of the Impact of PHY and MAC Parameters in 3GPP C-V2V Mode 4. IEEE Access 2018, 6, 71685-71698. [CrossRef]

9. Park, S.; Kim, B.; Yoon, H.; Choi, S. RA-eV2V: Relaying systems for LTE-V2V communications. J. Commun. Netw. 2018, 20, 396-405. [CrossRef]

10. Bazzi, A.; Masini, B.M.; Zanella, A.; Thibault, I. On the Performance of IEEE 802.11p and LTE-V2V for the Cooperative Awareness of Connected Vehicles. IEEE Trans. Veh. Technol. 2017, 66, 10419-10432. [CrossRef]

11. Noor-A-Rahim, M.; Ali, G.G.M.N.; Nguyen, H.; Guan, Y.L. Performance Analysis of IEEE 802.11p Safety Message Broadcast with and without Relaying at Road Intersection. IEEE Access 2018, 6, 23786-23799. [CrossRef]

12. He, J.; Tang, Z.; Fan, Z.; Zhang, J. Enhanced Collision Avoidance for Distributed LTE Vehicle to Vehicle Broadcast Communications. IEEE Commun. Lett. 2018, 22, 630-633. [CrossRef]

13. Bluetooth Special Interest Group. Bluetooth Core Specification Versions: 4.0; 4.1; 4.2. June 2010; December 2013; December 2014. Available online: https:/ / www.bluetooth.com/specifications/bluetoothcore-specification (accessed on 29 December 2018).

14. IEEE. IEEE Standard for Information Technology-Telecommunications and Information Exchange between Systems_Local and Metropolitan Area Networks-Specific Requirements Part 15.4: Wireless Medium Access Control (MAC) and Physical Layer (PHY) Specifications for Low-Rate Wireless Personal Area Networks (WPANs); Technical Report; IEEE: Piscataway, NJ, USA, 2006.

15. Iordache, V.; Gheorghiu, R.A.; Minea, M.; Cormos, A.C. Field testing of Bluetooth and ZigBee technologies for vehicle-to-infrastructure applications. In Proceedings of the 2017 13th International Conference on Advanced Technologies, Systems and Services in Telecommunications (TELSIKS), Nis, Serbia, 18-20 October 2017; pp. 248-251.

16. Abbasi, I.A.; Shahid Khan, A. A Review of Vehicle to Vehicle Communication Protocols for VANETs in the Urban Environment. Future Internet 2018, 10, 14. [CrossRef]

17. Demba, A.; Möller, D.P.F. Vehicle-to-Vehicle Communication Technology. In Proceedings of the 2018 IEEE International Conference on Electro/Information Technology (EIT), Rochester, MI, USA, 3-5 May 2018; pp. 0459-0464.

18. Silva, C.M.; Silva, L.D.; Santos, L.A.L.; Sarubbi, J.F.M.; Pitsillides, A. Broadening Understanding on Managing the Communication Infrastructure in Vehicular Networks: Customizing the Coverage Using the Delta Network. Future Internet 2018, 11, 1. [CrossRef]

19. Noh, S.; An, K.; Han, W. Toward highly automated driving by vehicle-to-infrastructure communications. In Proceedings of the 2015 15th International Conference on Control, Automation and Systems (ICCAS), Busan, Korea, 13-16 October 2015; pp. 2016-2021.

20. Corchero, C.; Sanmarti, M. Vehicle-to-Everything (V2X): Benefits and Barriers. In Proceedings of the 2018 15th International Conference on the European Energy Market (EEM), Lodz, Poland, 27-29 June 2018; pp. 1-4.

21. Bian, K.; Zhang, G.; Song, L. Toward Secure Crowd Sensing in Vehicle-to-Everything Networks. IEEE Netw. 2018, 32, 126-131. [CrossRef] 
22. Sanjana, T.; Fuad, K.A.A.; Habib, M.M.; Rumel, A.A. Automated anti-collision system for automobiles. In Proceedings of the 2017 International Conference on Electrical, Computer and Communication Engineering (ECCE), Cox's Bazar, Bangladesh, 16-18 February 2017; pp. 866-870.

23. Zhang, X.; Zeng, Q.; Meng, Q.; Xiong, Z.; Qian, W. Design and realization of a mobile seamless navigation and positioning system based on Bluetooth technology. In Proceedings of the 2016 IEEE Chinese Guidance, Navigation and Control Conference (CGNCC), Nanjing, China, 12-14 August 2016; pp. 1790-1793.

24. Tijerina, L.; Blommer, M.; Curry, R.; Swaminathan, R.; Kochhar, D.S.; Talamonti, W. An Exploratory Study of Driver Response to Reduced System Confidence Notifications in Automated Driving. IEEE Trans. Intell. Veh. 2016, 1, 325-334. [CrossRef]

25. Liu, M.; Naoum-Sawaya, J.; Gu, Y.; Lecue, F.; Shorten, R. A Distributed Markovian Parking Assist System. IEEE Trans. Intell. Transp. Syst. 2018, 99, 1-11. [CrossRef]

26. Arena, F.; Ticali, D. The development of autonomous driving vehicles in tomorrow's smart cities mobility. AIP Conf. Proc. 2018, 2040, 140007.

27. Silva, C.M.; Masini, B.M.; Ferrari, G.; Thibault, I. A Survey on Infrastructure-Based Vehicular Networks. Mob. Inf. Syst. 2017, 2017, 6123868. [CrossRef]

28. Festag, A. Cooperative intelligent transport systems standards in europe. IEEE Commun. Mag. 2014, 52, 166-172. [CrossRef]

29. Masini, B.M.; Bazzi, A.; Zanella, A. A Survey on the Roadmap to Mandate on Board Connectivity and Enable V2V-Based Vehicular Sensor Networks. Sensors 2018, 18, 2207. [CrossRef]

30. Sjoberg, K.; Andres, P.; Buburuzan, T.; Brakemeier, A. Cooperative Intelligent Transport Systems in Europe: Current Deployment Status and Outlook. IEEE Veh. Technol. Mag. 2017, 12, 89-97. [CrossRef]

31. Anaya, J.J.; Talavera, E.; Jimenez, F.; Zato, J.G.; Gomez, N.; Naranjo, J.E. GeoNetworking based V2V Mesh Communications over WSN. In Proceedings of the 16th International IEEE Conference on Intelligent Transportation Systems (ITSC 2013), The Hague, The Netherlands, 6-9 October 2013; pp. 2421-2426.

32. Zhang, E.D.L. Vehicle Stability Control System of Emergency Brake on Split-Mu Road. In Proceedings of the 2017 9th International Conference on Intelligent Human-Machine Systems and Cybernetics (IHMSC), Hangzhou, China, 26-27 August 2017; Volume 1, pp. 252-255.

33. Tornell, S.M.; Patra, S.; Calafate, C.T.; Cano, J.; Manzoni, P. A novel On-Board Unit to accelerate the penetration of ITS services. In Proceedings of the 2016 13th IEEE Annual Consumer Communications Networking Conference (CCNC), Las Vegas, NV, USA, 9-12 January 2016; pp. 467-472.

34. Boban, M.; d'Orey, P.M. Exploring the Practical Limits of Cooperative Awareness in Vehicular Communications. IEEE Trans. Veh. Technol. 2016, 65, 3904-3916. [CrossRef]

35. Ali, G.G.M.N.; Noor-A-Rahim, M.; Rahman, M.A.; Samantha, S.K.; Chong, P.H.J.; Guan, Y.L. Efficient Real-Time Coding-Assisted Heterogeneous Data Access in Vehicular Networks. IEEE Internet Things J. 2018, 5, 3499-3512. [CrossRef]

36. Ali, G.G.M.N.; Noor-A-Rahim, M.; Chong, P.H.J.; Guan, Y.L. Analysis and Improvement of Reliability Through Coding for Safety Message Broadcasting in Urban Vehicular Networks. IEEE Trans. Veh. Technol. 2018, 67, 6774-6787. [CrossRef]

37. Liu, G.; Wang, L.; Zou, S. A radar-based blind spot detection and warning system for driver assistance. In Proceedings of the 2017 IEEE 2nd Advanced Information Technology, Electronic and Automation Control Conference (IAEAC), Chongqing, China, 25-26 March 2017; pp. 2204-2208.

38. Cao, W.; Wu, Y.; Zhou, E.; Li, J.; Liu, J. Reliable Integrated ASC and DYC Control of All-Wheel-IndependentDrive Electric Vehicles over CAN Using A Codesign Methodology. IEEE Access 2018, 7, 6047-6059. [CrossRef]

39. Wang, C.; Song, C.; Li, J. Research on Key State Parameters Estimation of Electric Vehicle ESP Based on Multi-sensor. In Proceedings of the 2015 Fifth International Conference on Instrumentation and Measurement, Computer, Communication and Control (IMCCC), Qinhuangdao, China, 18-20 September 2015; pp. 29-32.

40. Lu, Y.; Yuan, Y.; Wang, Q. Forward Vehicle Collision Warning Based on Quick Camera Calibration. In Proceedings of the 2018 IEEE International Conference on Acoustics, Speech and Signal Processing (ICASSP), Calgary, AB, Canada, 15-20 April 2018; pp. 2586-2590.

41. Chao, C.; Qin, X. Research of vehicle automatic emergency braking system evaluation methods. In Proceedings of the IET International Conference on Intelligent and Connected Vehicles (ICV 2016), Chongqing, China, 22-23 September 2016; pp. 1-9. 
42. Kusano, K.D.; Gabler, H.C. Safety Benefits of Forward Collision Warning, Brake Assist, and Autonomous Braking Systems in Rear-End Collisions. IEEE Trans. Intell. Transp. Syst. 2012, 13, 1546-1555. [CrossRef]

43. Vinuchandran, A.V.; Shanmughasundaram, R. A real-time lane departure warning and vehicle detection system using monoscopic camera. In Proceedings of the 2017 International Conference on Intelligent Computing, Instrumentation and Control Technologies (ICICICT), Kannur, India, 6-7 July 2017; pp. 1565-1569.

44. Vehicle-To-Vehicle (V2V) Communication Market, by Connectivity Type, Deployment Type, Applications, End-Use, and Geography_Insights, Size, Share, Opportunity Analysis, and Industry Forecast till 2025. Coherent Market Insight, 26 October 2017.

45. Department of Transportation of the United States of America. Vehicle-To-Vehicle (V2V) Communications for Safety. Available online: https://www.its.dot.gov/research_archives/safety/v2v_comm_plan.htm (accessed on 29 December 2018).

46. Jurgen, R. V2V/V2I Communications for Improved Road Safety and Efficiency; SAE: Warrendale, PA, USA, 2012; pp. i-viii.

47. Rahman, K.A.; Tepe, K.E. Towards a cross-layer based MAC for smooth V2V and V2I communications for safety applications in DSRC/WAVE based systems. In Proceedings of the 2014 IEEE Intelligent Vehicles Symposium Proceedings, Dearborn, MI, USA, 8-11 June 2014; pp. 969-973.

48. Sepulcre, M.; Gozalvez, J.; Altintas, O.; Kremo, H. Context-aware heterogeneous V2I communications. In Proceedings of the 2015 7th International Workshop on Reliable Networks Design and Modeling (RNDM), Munich, Germany, 5-7 October 2015; pp. 295-300.

49. Department of Transportation of the United States of America. Vehicle-To-Infrastructure (V2I) Resources. Available online: https:/ / www.its.dot.gov/v2i/index.htm (accessed on 29 December 2018).

50. Tahmasbi-Sarvestani, A.; Mahjoub, H.N.; Fallah, Y.P.; Moradi-Pari, E.; Abuchaar, O. Implementation and Evaluation of a Cooperative Vehicle-to-Pedestrian Safety Application. IEEE Intell. Transp. Syst. Mag. 2017, 9, 62-75. [CrossRef]

51. Wu, C.; Yoshinaga, T.; Ji, Y.; Zhang, Y. Computational Intelligence Inspired Data Delivery for Vehicle-toRoadside Communications. IEEE Trans. Veh. Technol. 2018, 67, 12038-12048. [CrossRef]

52. Jomaa, D.; Yella, S.; Dougherty, M. A Comparative Study between Vehicle Activated Signs and Speed Indicator Devices. Transp. Res. Procedia 2017, 22, 115-123. [CrossRef]

53. Endo, M.; Tanaka, K. Evaluation of Storage Capacity of Electric Vehicles for Vehicle to Grid Considering Driver's Perspective. In Proceedings of the 2018 IEEE International Conference on Environment and Electrical Engineering and 2018 IEEE Industrial and Commercial Power Systems Europe (EEEIC/I CPS Europe), Palermo, Italy, 12-15 June 2018; pp. 1-5.

54. World Health Organization. Global Status Report on Road Safety; World Health Organization: Geneva, Switzerland, 2015.

55. Matsumoto, S.; Ohhigashi, N.; Hasuike, T. Developing a Transportation Support System for Vulnerable Road Users in Local Community. In Proceedings of the 2016 5th IIAI International Congress on Advanced Applied Informatics (IIAI-AAI), Kumamoto, Japan, 10-14 July 2016; pp. 797-800.

56. Pau, G.; Campisi, T.; Canale, A.; Severino, A.; Collotta, M.; Tesoriere, G. Smart Pedestrian Crossing Management at Traffic Light Junctions through a Fuzzy-Based Approach. Future Internet 2018, 10, 15.

57. Oliveira, T.R.; Silva, C.M.; Macedo, D.F.; Nogueira, J.M.S. SNVC: Social networks for vehicular certification. Comput. Netw. 2016, 111, 129-140. [CrossRef]

58. Kuo, Y.; Fu, C.; Tsai, C.; Lin, C.; Chang, G. Pedestrian Collision Warning of Advanced Driver Assistance Systems. In Proceedings of the 2016 International Symposium on Computer, Consumer and Control (IS3C), Xi'an, China, 4-6 July 2016; pp. 740-743.

59. Jung, H.; Choi, M.; Soon, K.; Jung, W.Y. End-to-end pedestrian collision warning system based on a convolutional neural network with semantic segmentation. In Proceedings of the 2018 IEEE International Conference on Consumer Electronics (ICCE), Las Vegas, NV, USA, 12-14 January 2018; pp. 1-3.

60. Dhondge, K.; Song, S.; Choi, B.; Park, H. WiFiHonk: Smartphone-Based Beacon Stuffed WiFi Car2X-Communication System for Vulnerable Road User Safety. In Proceedings of the 2014 IEEE 79th Vehicular Technology Conference (VTC Spring), Seoul, Korea, 18-21 May 2014; pp. 1-5.

61. Fire Angel. Wi-Safe Connect, 2018. Available online: https://www.wi-safeconnect.com/uk/ (accessed on 29 December 2018). 
62. Lee, J.H.; Park, M.; Shah, S.C. Wi-Fi direct based mobile ad hoc network. In Proceedings of the 2017 2nd International Conference on Computer and Communication Systems (ICCCS), Krakow, Poland, 11-14 July 2017; pp. 116-120.

63. Kinkade, S.; Naughton, C.; Pines, S.; Eagles, R. Honda Demonstrates Advanced Vehicle-To-Pedestrian and Vehicle-To-Motorcycle Safety Technologies. 2013. Available online: https://www.prnewswire.com/ news-releases / honda-demonstrates-advanced-vehicle-to-pedestrian-and-vehicle-to-motorcycle-safetytechnologies-221495031.html (accessed on 29 December 2018).

64. Nguyen, H.; Noor-A-Rahim, M.; Liu, Z.; Jamaludin, D.; Guan, Y.L. A Semi-Empirical Performance Study of Two-Hop DSRC Message Relaying at Road Intersections. Information 2018, 9, 147. [CrossRef]

65. General Motors. GM Developing Wireless Pedestrian Detection Technology. 2012. Available online: https://media.gm.com/media/us/en/gm/home.detail.html/content/Pages/news/us/en/2012/Jul/ 0726_pedestrian.html (accessed on 29 December 2018).

66. Mare, R.M.; Marte, C.L.; Cugnasca, C.E. Visible Light Communication Applied to Intelligent Transport Systems: An Overview. IEEE Lat. Am. Trans. 2016, 14, 3199-3207. [CrossRef]

67. Cailean, A.; Dimian, M. Current Challenges for Visible Light Communications Usage in Vehicle Applications: A Survey. IEEE Commun. Surv. Tutor. 2017, 19, 2681-2703. [CrossRef]

68. Yamazato, T.; Takai, I.; Okada, H.; Fujii, T.; Yendo, T.; Arai, S.; Andoh, M.; Harada, T.; Yasutomi, K.; Kagawa, K.; et al. Image-sensor-based visible light communication for automotive applications. IEEE Commun. Mag. 2014, 52, 88-97. [CrossRef]

69. Bazzi, A.; Masini, B.M.; Zanella, A.; Calisti, A. Visible light communications as a complementary technology for the internet of vehicles. Comput. Commun. 2016, 93, 39-51. [CrossRef]

70. Anayor, C.; Gao, W.; Odekunle, A. Cooperative Adaptive Cruise Control of A Mixture of Human-driven and Autonomous Vehicles. In Proceedings of the IEEE SoutheastCon 2018, St. Petersburg, FL, USA, 19-22 April 2018; pp. 1-3.

71. Rezwan, M.S.; Islam, M.A.; Islam, M.M.; Hasan, M.R. Vehicle Breaking Support System. In Proceedings of the 2018 3rd International Conference for Convergence in Technology (I2CT), Pune, India, 6-7 April 2018; pp. 1-4.

72. Asuzu, P.; Thompson, C. Road condition identification from millimeter-wave radar backscatter measurements. In Proceedings of the 2018 IEEE Radar Conference (RadarConf18), Oklahoma City, OK, USA, 23-27 April 2018; pp. 0012-0016.

73. Yoshioka, M.; Suganuma, N.; Yoneda, K.; Aldibaja, M. Real-time object classification for autonomous vehicle using LIDAR. In Proceedings of the 2017 International Conference on Intelligent Informatics and Biomedical Sciences (ICIIBMS), Okinawa, Japan, 24-26 November 2017; pp. 210-211.

74. Bronzi, W.; Derrmann, T.; Castignani, G.; Engel, T. Towards characterizing Bluetooth discovery in a vehicular context. In Proceedings of the 2016 IEEE Vehicular Networking Conference (VNC), Columbus, OH, USA, 8-10 December 2016; pp. 1-4.

75. Collotta, M.; Pau, G.; Talty, T.; Tonguz, O.K. Bluetooth 5: A Concrete Step Forward toward the IoT. IEEE Commun. Mag. 2018, 56, 125-131. [CrossRef]

76. Chen, S.; Hu, J.; Shi, Y.; Peng, Y.; Fang, J.; Zhao, R.; Zhao, L. Vehicle-to-Everything (v2x) Services Supported by LTE-Based Systems and 5G. IEEE Commun. Stand. Mag. 2017, 1, 70-76. [CrossRef]

(C) 2019 by the authors. Licensee MDPI, Basel, Switzerland. This article is an open access article distributed under the terms and conditions of the Creative Commons Attribution (CC BY) license (http:/ / creativecommons.org/licenses/by/4.0/). 